EPJ Web of Conferences 110,01058 (2016)

DOI: $10.1051 /$ epjconf/201611001058

(C) Owned by the authors, published by EDP Sciences, 2016

\title{
TERMS AND CHARACTERISTICS OF HOMOGENEOUS IGNITION OF COAL- WATER PARTICLES COATED WITH A WATER FILM
}

\author{
S.V Syrodoy ${ }^{1, a}$, N.Y. Gutareva ${ }^{1}$, R.I.Taburchinov ${ }^{1}$, K.A. Bugaeva ${ }^{1}$ \\ ${ }^{1}$ National Research Tomsk Polytechnic University, 634050 Tomsk, Russia
}

\begin{abstract}
The problem of coal-water fuel ignition of particles in a high-temperature heating has been solved numericallyin the framework of a two-layer model of "coal-water". The basic characteristics of the integrated ignition has been shown. The influence of the vaporization process of the water film on the ignition conditions has been shown.
\end{abstract}

\section{Introduction}

One of the most promising ways to reduce the environmental load of thermal power plants (TPP) (reducing emissions of nitrogen oxides and sulfur) coal power plants, both in Russia [1] and abroad [2] is the transition from the traditional ways of organizing combustion (e.g., flaring [3] or layers [4]) to the burning of coal in the various fuel compositions, for example - coal-water fuel (CWF). Despite a long history of development of this technology (the beginning of work on the WCF dates back to the year 1959 [5]), it has not been widespread in the modern thermal power plants (with the possible exception of China and Japan). Likely, it is a consequence of poor drafting of basic aspects of the theory of ignition and burning of complex way designed (multicomponent) and essentially inhomogeneous (on the fractional composition and physical state of the components) fuels.

Designed to date model ignition [2, 6-8] drops of WCF are based on the hypothesis of a uniform distribution in the amount of the basic elements of the system "water - organic and mineral part of fuel". However, it has been established experimentally [9] in the process of spraying the fuel in the combustion chamber may be formed of water-coal particles, which are "pillars" [9] (homogeneous particle) carbon coated with a thin film of water. The likelihood of such a configuration is quite high ( $\mathrm{P} \geq 50 \%)$ [9], due to the nature modes of training systems and fuel atomization. It is obvious that the mechanism of ignition particles WCF will differ significantly from the ignition of solid [10] (dry coal, wood) and liquid (oil, diesel fuel) [11] fuels. It's safe to say that a drop of WCF will not ignite until complete evaporation of the surface of the film. Accordingly, there is a high probability of formation of inhomogeneous (temperature) torch [to the presence of "cold zones" (most likely in the initial section of flow)].

As a result, there are risks of violation of temperature combustion. As a consequence of possible open flame. [12] In this case it is necessary to stabilize the temperature field of the torch through the fuel [13] (gas, fuel oil) or electromagnetic [14] (microwave, plasma) "illumination". The latter is very difficult and leads to an increase in expenses for reconstruction and operation of the boiler equipment.

The purpose of our work - mathematical modeling of ignition of coal-water fuel particles in a corresponding firing installations boiler as part of a two-layer structure of the "coal — water" and the definition of the main characteristics and conditions of the ignition of such a particle WCF.

\section{Physical and Mathematical Statement}

At the initial time $(t=0)$, a drop of coal-water fuel is in a corresponding combustion chamber of the boiler unit. Under the influence of convection and radiation heat flux near surface film of water begins to evaporate. As a result, the particle size decreases. Evaporation rate (and hence the thermal effect of the phase transition) depend on the temperature of the surface water layer. The process of thermal decomposition and ignition is initiated after removing of the film particles WCF in a continuing heating process. It is assumed that particles on the surface of carbon oxidation reaction occurs:

$$
\mathrm{C}+\mathrm{O}_{2}=\mathrm{CO}_{2}+402,4 \kappa Д \% \kappa / \kappa \mathrm{g}
$$

The mathematical formulation of the problem, the corresponding stated higher of physical model is a non-stationary system of differential equations in partial derivatives:

- $\quad$ energy equation for a homogeneous coal:

\footnotetext{
${ }^{a}$ Corresponding author: ssyrodoy@yandex.ru
} 


$$
\begin{gathered}
C_{1} \rho_{1} \frac{\partial T_{1}(r, t)}{\partial t}=\lambda_{1} \cdot\left[\frac{\partial^{2} T_{1}(r, t)}{\partial r^{2}}+\frac{2}{r} \cdot \frac{\partial T_{1}(r, t)}{\partial r}\right] \pm \sum Q_{i} \cdot W_{i}, \\
t>0,0<r<r_{1}, T \leq T_{w-c}
\end{gathered}
$$

the equation of chemical kinetics for homogeneous coal:

$$
\begin{gathered}
\frac{\partial \eta_{1}(r, t)}{\partial t}=\left(1-\eta_{1}(r, t)\right) \cdot k_{i} \cdot \exp \left(-\frac{E}{R \cdot T_{1}(r, t)}\right) \\
t>0,0<r<r_{1}, T \leq T_{w-c}
\end{gathered}
$$

energy equation for the film of water:

$$
\begin{gathered}
C_{2} \rho_{2} \frac{\partial T_{2}(r, t)}{\partial t}=\lambda_{2} \cdot\left[\frac{\partial^{2} T_{2}(r, t)}{\partial r^{2}}+\frac{2}{r} \cdot \frac{\partial T_{2}(r, t)}{\partial r}\right] \\
t>0, r_{1}<r<r_{0}, T \geq T_{1}
\end{gathered}
$$

There is 4 the boundary condition of the fourth kind at the interface of the "homogeneous coal — water film":

$$
\begin{gathered}
\left.\lambda_{1} \frac{\partial T_{1}(r, t)}{\partial r}\right|_{r=r_{0}-0}=\left.\lambda_{2} \frac{\partial T_{2}(r, t)}{\partial r}\right|_{r=r_{0}+0} \\
T_{1}\left(r_{0} ; t\right)=T_{2}\left(r_{0} ; t\right)=T_{w-c}
\end{gathered}
$$

The system of equations (1-3) has been solved with the following boundary conditions and closing ratios:

$$
\begin{array}{r}
0<r<r_{0}, T(r, 0)=T_{0}, \eta(r, 0)=\eta_{0}, \\
-\left.\lambda_{2} \frac{\partial T_{2}\left(r_{u}, t\right)}{\partial r}\right|_{r=r_{u}}=\alpha \cdot\left[T_{c}-T_{2}\left(r_{u}, t\right)\right]+\varepsilon \cdot \sigma \cdot\left[T_{c}^{4}-T_{2}^{4}\left(r_{u}, t\right)\right]-Q_{v} W_{v} \\
-\left.\lambda_{1} \frac{\partial T_{1}\left(r_{0}, t\right)}{\partial r}\right|_{r=r_{0}}=\alpha \cdot\left[T_{c}-T_{1}\left(r_{0}, t\right)\right]+\varepsilon \cdot \sigma \cdot\left[T_{c}^{4}-T_{1}^{4}\left(r_{0}, t\right)\right] \\
\frac{\partial T_{1}(0, t)}{\partial r}=0
\end{array}
$$

The rate of chemical reactions has been calculated from the mathematical expression of the Arrhenius law:

$$
W=k \cdot \rho_{1} \cdot \exp \left(-\frac{E}{R \cdot T_{1}(r, t)}\right),
$$

The designations: $\mathrm{T}_{0}-$ are the initial temperature of the particles, $\mathrm{K} ; \mathrm{T}_{\mathrm{c}}-$ is the temperature of the environment, $\mathrm{K} ; \mathrm{T}_{w-c}-$ is the temperature at boundary section of the "coal - water", $\mathrm{K} ; \mathrm{r}_{1}$ - coal particle radius, $\mathrm{m} ; \mathrm{r}_{0}-$ external WCF particle radius, m; $\varepsilon-$ is a constant radiation of a black body; $\quad \alpha-$ coefficient of convective heat transfer, $W /\left(\mathrm{m}^{2} \cdot \mathrm{K}\right) ; \lambda_{1}-$ the coefficient of 
thermal conductivity of the homogeneous part of the WCF, $W /(m \cdot K) . \lambda_{2}$ - the coefficient of thermal conductivity of water, $\mathrm{W} /(\mathrm{m} \cdot \mathrm{K}) ; \mathrm{C}_{1}$ - specific heat homogeneous part of $\mathrm{WCF}, \mathrm{J} /(\mathrm{kg} \cdot \mathrm{K}) ; \mathrm{C}_{2}-$ the specific heat of water, $J /(\mathrm{kg} \cdot \mathrm{K}) ; \mathrm{W}_{\mathrm{eva}}-$ mass the rate of evaporation of water, $\mathrm{kg} /\left(\mathrm{m}^{2} \cdot \mathrm{s}\right) ; \mathrm{Q}_{\mathrm{eva}}-$ is the thermal effect of the evaporation of water, $J / \mathrm{kg} ; \mathrm{Q}_{\mathrm{i}}-$ is the thermal effect of chemical reaction, $J / \mathrm{kg} ; \mathrm{k}_{\mathrm{i}}$ - preexponent chemical reaction $1 / \mathrm{s} ; \mathrm{E}_{\mathrm{i}}$ - the activation energy of a chemical reaction, $\mathrm{J} /$ mole;

The mass evaporation rate has been calculated from the expression [6-8]:

$$
W_{\text {eva }}=W_{0} \cdot \exp \left[\frac{Q_{\text {eva }} \cdot \mu \cdot\left(T\left(r_{u}, t\right)-T_{0}\right)}{R \cdot T_{0} \cdot T\left(r_{u}, t\right)}\right],
$$

Where: $\mathbf{T}_{\mathbf{1}}-$ is the temperature at the boundary of evaporation, $\mathrm{K} ; \mathbf{T}_{\mathbf{0}}-$ is the temperature of the liquid corresponding to the freezing point, $\mathrm{K} ; \mathbf{W}_{\mathbf{0}}$ - the velocity of evaporation at a temperature, $\boldsymbol{k g} /\left(\mathbf{m}^{\mathbf{2}} \cdot \mathbf{s}\right) ; \boldsymbol{\mu}-$ molar Mass of water vapor, $\boldsymbol{k g} / \mathbf{m o l e} ; \mathrm{R}$ - universal gas constant, $\mathrm{J} /(\boldsymbol{m o l e} \cdot \boldsymbol{K})$.

The system of nonlinear equations (1) - (9) has been solved by finite difference method [15], in two stages. The first problem of evaporation [on the heating surface applied boundary condition (6)] in the second ignition [on the outer boundary condition (7)] has been solved.

Figure 1 shows the dependence on the delay time of ignition homogeneous water coal particles coated with a water film, the temperature of the environment. The particle size has been varied within a fairly wide (but at the same time, most likely for the modern nozzle technology [9]) the range of $\delta=0,1 \div 0,5 \cdot 10^{-3} \mathrm{~m}$. Dependency analysis (Fig. 1) shows that the temperature of the external oxidant has a significant impact on the dynamics of the processes of preparation and thermal ignition particulate of WCF. So we can say that for a particle diameter of $\delta=0,5 \cdot 10^{-3} \mathrm{~m}$ temperature increase at $500 \mathrm{~K}$ (from $900 \mathrm{~K}$ to $1400 \mathrm{~K}$ ), significantly accelerates ignition [approximately $5-6$ times (delay time decreases from 16 seconds to 3 )]. The latter can indicate the important role of the complex processes of evaporation of the water film, the warm of base layer of fuel and the thermal decomposition of the organic carbon in the temporal characteristics of the thermal treatment steps. At the same time it should be noted that in case of fire drops WCF diameter $\delta=0,1 \cdot 10^{-3} \mathrm{~m}$, the degree of this influence is negligible, which may also indicate the important role of the temperature distribution along the radius of the particle. Consequently, the application of balance-type models [16] during the predictive modeling of ignition of fuel can lead to large errors in determining the ignition delay times.

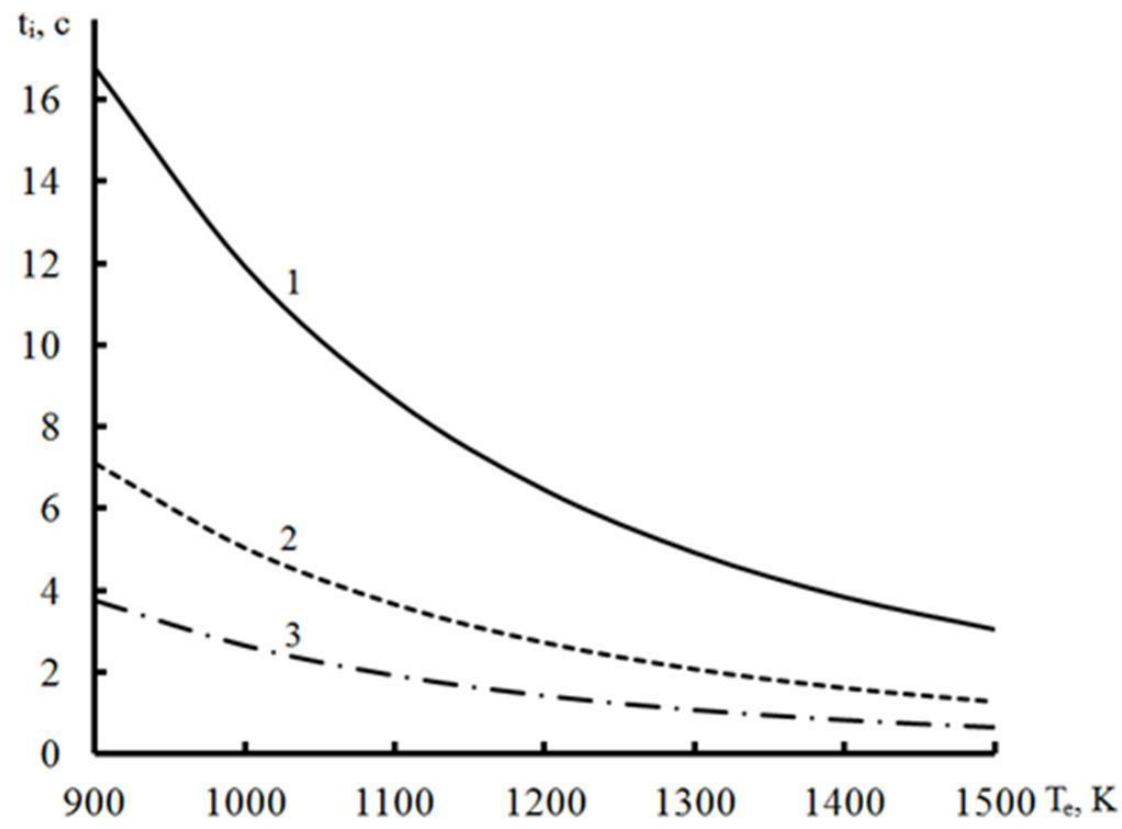

Figure.1. The dependence of the ignition delay times of the ambient temperature at a rate $(\delta)$ particles: $1-0,5 \cdot 10^{-3} \mathrm{~m} ; 2-0,2 \cdot 10^{-3} \mathrm{~m} ; 3-0,1 \cdot 10^{-3} \mathrm{~m}$. 


\section{EPJ Web of Conferences}

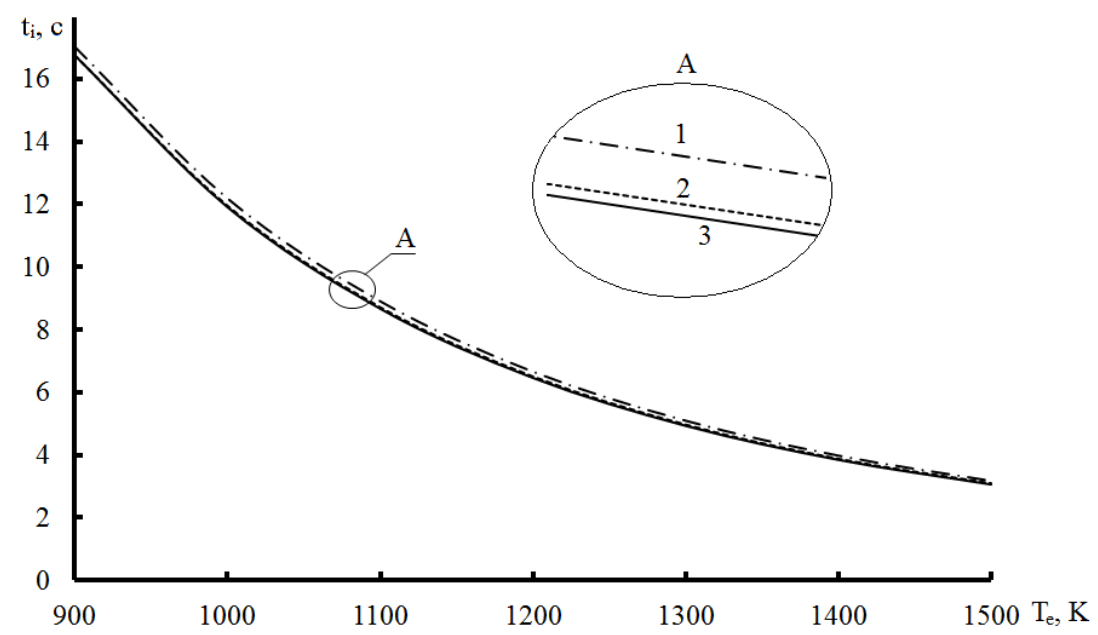

Figure.2. The dependence of the ignition delay times particle diameters rum $(\delta=0,5 \cdot 10-3 \mathrm{~m})$ on the ambient temperature at a film thickness $(\Delta): 1-0,15 \cdot 10^{-3} \mathrm{~m} ; 2-0,1 \cdot 10^{-3} \mathrm{~m} ; 3-0,05 \cdot 10^{-3} \mathrm{~m}$.

Figure 2 shows the dependence of $t_{i}$ (particles of coal-water fuel diameter $\delta=0,1 \cdot 10^{-3} \mathrm{~m}$ ) on the ambient temperature by varying the thickness of the water film $\left(\Delta=0,05 \div 0,15 \cdot{ }^{10}-3 \mathrm{~m}\right)$. The analysis of the relationship shows that the film of water affects the dynamics of the thermal preparation and ignition, but the extent of this impact is negligible. Thus, when the ambient temperature $_{\mathrm{T}} \mathrm{e}=1100 \mathrm{~K}$ threefold increase in the thickness of the water layer (with 0.05 to $0.15 \cdot 10^{-3} \mathrm{~m}$ ) leads to a slight increase in the induction period. Likely, it indicates that the base layer of heating fuel occurs when the water film is upon evaporation. Accordingly, the following initiation of combustion of the coal particles (already "dehydrated") proceeds considerably faster.

\section{Conclusion}

According to the results of numerical modeling the basic temporal characteristics of processes of heat and ignition homogeneous preparation of coal-water fuel particles coated with a water film have been set up. It has been shown that an increase in the thickness of the water film has a negligible ( 0.1 to $2 \%$ ) impact on the delay time of ignition. The latter, probably due to the fact that the evaporation of the water film occurs heating of the base layer of fuel, resulting in subsequent ignition "dehydrated" particles is faster than the same particles of the dry coal.

The research has been carried out at the expense of the grant of the Russian Science Foundation (project № 15-19-10003).

\section{References}

1. G.S. Khodakov, Thermalenergy, 1, (2007).

2. Agnieszka Kijo - Kleczkowska, Fuel, 90, (2011).

3. M. Norbert, M. Pawel, J. Tomasz, S. Krzysztof, K. A. Wlodzimierz, Energy, In Press, Corrected Proof, (2015)

4. J. Van Caneghem, A. Brems, P. Lievens, Progress in Energy and Combustion Science, 38, 4, (2012)

5. V. F. Kustov Water-fuel suspension (Works at area chemical technologies fuel. L.: Goskhimizdat, 1959)

6. V.V. Salomatov, S.V. Syrodoy, N. Y. Gutareva, EPJ Web of Conferences, 76, 01018 (2014)

7. V.V. Salomatov, S.V. Syrodoy, N.Y. Gutareva, IOP Conf. Series: Materials Science and Engineering, 66, 012040 (2014)

8. V.V. Salomatov, S.V. Syrodoy, N.Y. Gutareva, EPJ Web of Conferences, 82, 01037 (2015)

9. U.A. Senchurova, Improved combustion technology of coal water fuel at vortex furnaces (Author. Dis. ... Cand. tehn. Sciences., 2008) [In Russia]

10. K. Suresh Aggarwal, Progress in Energy and Combustion Science, 45, (2014)

11. Hui Liu, Zhi Wang, Yan Long, Shouzhi Xiang and etc, Fuel, 159, (2015)

12. A.A. Alechenu, J.H. Kevin, B.I. Derek, A study of Numerical wake-stabilized propane flame in a cross-flow of air journal of the Energy Institute, ( In Press, Uncorrected Proof, Available online, 2015)

13. A. A. Völker, M. C. Pronin, A. A. Matveev, A. E. Schlegel, Warm power, 3, (1991)

14. Esakov I., Grachev L., Khodataev K., Van Wie D. Experiments on propane ignition in high-speed airflow using a deeply under critical microwave discharge. In: 42nd AIAA aerospace sciences meeting including the new horizons forum and aerospace exposition, (Reno, Nevada, 2004)

15. M.A. Sheremet, Paired tasks natural convection. Deputy to the mentioned region with local sources of heat (LAP LAMBERT Academic Publishing, 2011)

16. Chen Lei, Progress in Energy and Combustion Science, 38, 2 (2012) 